Open Access

\title{
Does university entrepreneurship work in Japan?: a comparison of industry-university research funding and technology transfer activities between the UK and Japan
}

Tatsuya Ito $^{1 *}$, Takashi Kaneta ${ }^{2}$ and Sue Sundstrom ${ }^{1}$

* Correspondence:

taito@kuhp.kyoto-u.ac.jp

${ }^{1}$ Research and Enterprise Development, University of Bristol, Tyndall Avenue, Bristol BS8 1TH, UK Full list of author information is available at the end of the article

\section{说 Springer}

\begin{abstract}
Entrepreneurship in Japanese universities has changed radically over the last 15 years, following the introduction of an equivalent to the Bayh-Dole Act in 1999. However, it is still unclear whether Japanese entrepreneurship is working. There are some publications that focus on the entrepreneurship environment in the early of 2000s by comparing Japan and other countries, but none in the last decade. In this study, we show that the national economic situation and university size are very similar between the UK and Japan. We compare university research funding and intellectual property income, numbers relating to patents, licences granted, and spin-offs between the UK and Japan nationally and between two specific universities. Japanese universities' entrepreneurship has improved over the past 10 years, and the trend remains positive. However, Japanese universities currently possess, arguably, too many patents and also receive relatively low income from patents, resulting in significant pressure on their budgets. The number of Japanese spin-offs created fell significantly between 2005 and 2010, since when the number has remained at around 50 per year. We expect that Japanese entrepreneurship could improve by implementing a review of patent strategy and technology transfer processes, improvement of technology transfer skills, and governmental activity.
\end{abstract}

Keyword: Entrepreneurship, Technology transfer, Research fund, Patent, Revenue, Spin-off

\section{Background}

Universities have a number of opportunities and mechanisms to share know-how and develop new ideas. Since the Bayh-Dole Act was introduced in 1980 in the USA, US universities own intellectual property (IP) resulting from government funded research. The Act created a uniform public patent policy allowing publicly funded research to be patented by universities, and brought US universities the rights to own and license patents. Many other countries have now introduced similar legal rights so that their universities own IP created through their government funded research. The environment within universities and academic and university attitudes towards commercialisation have changed radically across the world over the past decade, as universities have

(C) 2016 Ito et al. Open Access This article is distributed under the terms of the Creative Commons Attribution 4.0 International License (http://creativecommons.org/licenses/by/4.0/), which permits unrestricted use, distribution, and reproduction in any medium, provided you give appropriate credit to the original author(s) and the source, provide a link to the Creative Commons license, and indicate if changes were made. 
written policies, built technology transfer (TT) offices and gained experience transferring university-generated technology and IP to the commercial sector.

It is evident from our analysis that governments fully recognise the concept of 'Triple Helix' innovation wherein 'the potential for innovation and economic development in a Knowledge Society lies in a more prominent role for the university and in the hybridisation of elements from university, industry and government to generate new institutional and social formats for the production, transfer and application of knowledge'. For example in a speech in 2014 David Willets, UK Universities and Science minister (Willets 2014) said 'But today ...... We are focusing on the fact that universities are also powerhouses for economic growth.' They are a vital part of the government's long-term economic plan to build a more resilient economy and create jobs. Similarly, in the 4th Science and Technology Basic Plan of Japan, the Ministry of Education, Culture, Sports, Science and Technology (MEXT) demonstrated enhancement of knowledge networks among industrial sector, academic sector and government, and improvement of circumstances for strengthening of support for commercialization (MEXT 2011). Our recommendations feed into the balance between the elements of the Triple Helix, and are intended to improve the benefits of university entrepreneurship to industry, universities and the economy. We also recognise that the fourth element addressed in the quadruple helix model i.e. 'media-based and culture-based public' and 'civil society' and the broader 'natural environments of society' (Carayannis et al. 2012), will be of importance in local and national priorities and preferred implementation plans, but a detailed analysis of how such variables impact university entrepreneurship in the UK, Japan and more broadly has not been addressed in this paper. It is broadly recognised that research outcomes from universities should be accepted by the public and be of economic, social, environmental or political benefit to society. This concept is now embedded in the UK Research Excellence Framework (REF) which includes an assessment of the impact on research, the results of which feed into university core funding by the UK government (REF impact 2014).

However, the processes from new idea to IP protection are still quite complicated in many universities. It is also difficult for universities to decide which research outcomes should be protected via patenting or other IP protection since the university is unlikely to directly sell the final product protected by the IP. There is no simple, linear development process. In addition, it can be hard to find and employ specialists who understand both the research mind and commercialisation needs. These are similar issues faced by universities all over the world.

There is some literature that focuses on a comparison of the university entrepreneurship environment internationally, such as policies, IP rights and TT, between USA and UK (Decter et al. 2007), between USA and Japan (Kneller 2007), and among European countries (Geuna and Rossi 2011). It has been widely believed, until relatively recently, that Bayh-Dole-like models are the best way to ensure the commercialization of university inventions and the effects of implementing such acts have been examined in the literature (Geuna and Nesta 2006 and Mowery and Sampat 2005). It is interesting to note that there are four examples where Bayh-Dole-like models have not been implemented or have not been successful: Cambridge, UK (Breznitz 2011), Japan (Takahashi and Carraz 2009), Denmark (Valentin and Jensen 2007), and Sweden (Jacobsson et al. 2013 but this lack of a Bayh-Dole act has not significantly affected entrepreneurial activity in these universities/countries). Even in the USA, there is some evidence that 
the involvement of TTOs may slow down the commercialisation process due to a keenness to safeguard researchers' interests and maximise university returns (Siegel et al. 2007). Researchers in USA and European countries have recently favoured entrepreneurial start-ups rather than commercialisation via technology transfer and licencing (Bergman 2010 and Looy et al. 2011). In the UK, university researchers interact with industry using a wide variety of channels, and engage more frequently in the majority of the channels examined, such as contract research, joint research, consulting, or training, with only a minority of such interaction relating to patenting or spin-out activities (D'Este and Patel 2007).

In Japan, engineering and materials/chemistry inventions in universities typically arise from collaborations with large companies, limiting opportunities for spin-off company or start-up company formation or for licensing to small companies (Kneller 2007). There are varieties of TT and knowledge transfer activities between the economic developed countries, like the UK and Japan, which are not appropriate for the Bayh-Dole-like model. But there is not any recent literature which compares the UK and Japan.

Interestingly, despite quite different population numbers (UK; 63.7 million in 2012, ${ }^{1}$ Japan 127.5 million in $2012^{2}$ ), the numbers of students both undergraduate and postgraduate and of staff both academic and non-academic are of a similar scale in the two countries which facilitates the direct comparison made in this paper since we focus on university entrepreneurship, rather than any society-wide analysis.

The purpose of this study is to examine Japanese universities' entrepreneurship work in the last decade through a comparison of university research funding and technology transfer activity between the UK and Japan. First, we compare the environment for research commercialisation in the UK and Japan in the Environment section. In the 'Results and discussion' section, we analyse, using public data available in both countries, the development of university collaborative research funds, patent applications, income from IP and the creation of spin-offs in the 'Comparisons of industry-university collaboration in the UK and Japan' section. Next, we focus on the whole process of TT activity in the two universities, Kyoto University in Japan and University of Bristol in the UK in the 'Comparisons of technology transfer and industry-university collaboration in UoB and KU' section. In the end of the section, we summarise and discuss this comparison. And finally, in the 'Conclusions' section, we suggest some conclusions and recommendations. Then we show the data sources and describe definitions of research funding and enterprise size in both countries in the 'Methods' section.

\section{Environment}

\section{Legislation and national frameworks}

In the UK, there has traditionally been a strong focus on the publication of papers by academics rather than on patenting or the commercialisation of research, particularly in 'research intensive' universities.

The UK Patent Act 1977 states that an employee's invention made in the course of their duties' is owned by the employer; there is no different provision for academics working for universities, so a UK university owns, through the patent act, the inventions of its employees. Despite the legal position, a government organisation, the National Research Development Corporation (NRDC) set up in 1948, managed intellectual property rights 
generated by academics. In 1981, NRDC merged with the National Enterprise Board to form the British Technology Group (BTG). BTG gained the exclusive rights to commercialise the results of publicly funded research until 1985 when UK universities were allowed to decide whether to own and manage their patents independently or continue to rely on the services provided by BTG (Macdonald 2009). In 1992, BTG was privatised as a supplier of IP services to universities and other companies. In 1993, the UK Department of Trade and Industry (DTI) published a White Paper called 'Realising our potential (DTI 1993), calling for universities to play a key role in national innovation and competitiveness. Recent UK government policy has included programmes to encourage knowledge transfer from universities to industry (DTI 2001). Governmental initiatives, such as 'University Challenge' (which provided seed funding) and HEROBC or HEIF (which build knowledge transfer capabilities in universities), have encouraged universities, through the provision of funding, to undertake commercialisation activities (Salter et al. 2000). UK universities now increasingly exert their property rights over inventions and have employed significant numbers of technology transfer officers.

The UK has an influential support organisation-Innovate UK (previously known as the Technology Strategy Board or TSB). The role of Innovate UK is to accelerate economic growth by stimulating and supporting business-led innovation. Innovate UK provides grants to companies to support technology led growth, often with universities as partners, offering both a mechanism to build commercial partnerships for universities and also a route to commercialise research. Innovate UK particularly focuses on small and medium enterprises (SMEs) and small business and is an important factor in the creation of spin-offs. The UK government has identified SMEs as a major source of the UK's future economic growth. Innovate UK supports SMEs, including spin-offs, by helping them access finance, partners, lead customers, market knowledge, and skills. One long-running programme run by Innovate UK, of specific interest to university research commercialisation, is 'Knowledge Transfer Partnerships (KTP)' a UK-wide programme which aims to improve the competitiveness of a business by drawing on the expertise in UK universities. KTP offers a knowledge transfer mechanism by providing higher education institutions with the unique opportunity to apply research to the real-world business projects. A KTP aims to deliver significant increased profitability for business partners as a direct result of the partnership through improved quality and operations, increased sales and access to new markets.

In order to encourage commercial skill development and improvement across all universities engaged in commercialisation, the sector has set up, an educational notfor-profit organisation, PraxisUnico, which supports innovation and commercialisation in the public sector by the sharing between organisations of good practice. PraxisUnico delivers an annual programme of training events for commercialisation professionals, run largely by very experienced practitioners, in order to share information and discuss various issues current among higher education institutions.

In Japan, the Japanese government led the industry-university collaborations policy in the late 1990s through the TLO Act in 1998 and the Japanese Bayh-Dole Act in 1999, almost 20 years after the US Bayh-Dole Act was introduced in 1980. The Japanese Bayh-Dole Act has allowed universities to retain invention rights resulting from government-funded research. In 2004, another evolution was introduced when all Japanese national universities incorporated, which means that each university can drive not only research and education 
but also industry-university collaboration and IP management (Shimoda 2005; Motohashi and Muramatsu 2012). To develop commercialisation activity, universities started building infrastructure, in the form of Technology Licensing Offices (TLOs) responsible for IP management and TT. The TLOs employ staff with commercial skills. Beginning with five in 1998, the number of approved TLOs had risen to 41 by 2005 (Walsh et al. 2008) and by 2009 a total of 47 TLOs were approved by the Ministry of Education, Culture, Sport, Science and Technology (MEXT) and the Ministry of Economy, Trade and Industry (Motohashi and Muramatsu, 2012).

University-owned inventions could be licensed through the affiliated TLO, most of which are now private companies wholly owned by a university. The TLOs often also provide support to their host and other universities in the development of partnerships with industry. Most TLOs are members of the University Network for Innovation and Technology Transfer (UNITT). UNITT provides services, such as IP management and technology transfer, exchanging information, raising awareness, and education. The members are composed of universities, TLOs corporations, organisations, and individuals.

\section{Size of the university sector in UK and Japan}

Prior to commencing this survey, we compared the size of the university sector in the UK and Japan. To do this, we compared the numbers of universities, staff, and students, in each country in Table 1. UK data are taken from the Higher Education Statistics Agency, Online Statistics 2012-13, and Japanese, data is from the Statistics Data of the MEXT 2013. There is a distinct difference in that the number of universities in Japan is about seven times higher than in the UK. However, the total numbers of students and staff are similar. We therefore suggest that the outcomes and tendencies of the two countries can validly be compared in this survey.

We also looked at GDP, one of the economic standards, in the UK and Japan in 2012. ${ }^{3}$ The GDP for 2012 was $\$ 2615$ billion for the UK, about half that of Japan at $\$ 5954$ billion in 2012. GDP per person is almost the same in the UK and Japan, suggesting that the economic environment in the two countries is similar.

\section{University of Bristol and Kyoto University}

For the purposes of this study, we chose to compare the University of Bristol and Kyoto University for the following reasons: according to the World University rankings, such as Academic Ranking of World Universities by Shanghai Jiao Tong in 2014, the Times Higher Education World University Rankings in 2014 and the QS World University Rankings 2014, both universities are positioned among the top 100 research intensive universities worldwide. In addition, the University of Bristol and Kyoto University signed a general memorandum for research commercialisation in 2008, and for academic exchange and cooperation in 2011. Our objective here is to understand and share the systems and processes for research commercialisation in both countries in

Table 1 A comparison of university populations in the UK and Japan

\begin{tabular}{|c|c|c|c|c|c|c|}
\hline & \multirow{2}{*}{$\begin{array}{l}\text { The } \\
\text { number of } \\
\text { universities }\end{array}$} & \multicolumn{2}{|c|}{ The number of students } & \multicolumn{3}{|c|}{ The number of staff } \\
\hline & & Undergraduate & Postgraduate & Total & Academic & Non-academic \\
\hline UK & 161 & $2,340,275$ & 536,440 & 382,520 & 185,585 & 196,935 \\
\hline Japan & 1141 & $3,065,358$ & 306,804 & 411,762 & 187,300 & 244,462 \\
\hline
\end{tabular}


order to learn from each other and to improve how we turn global research collaboration outcomes into significant innovations in the future.

University of Bristol (UoB), was created formally by charter in 1909, is a research intensive university located in Bristol in South-West England and is a member of the Russell Group, which is a university association comprised of 24 leading British universities. UoB has six faculties: Arts, Engineering, Medical and Veterinary, Medicine and Dentistry, Science, and Social Science and Law. UoB is associated with 11 Nobel Laureates. In UoB, the Research and Enterprise Development (RED) takes responsibility for research services, helping academics, students and entrepreneur communities both within and outside of UoB to maximise their activities. RED does this through multi-disciplinary teams of professionals who use their expertise and knowledge to provide advice, guidance and support across the broad and diverse research and enterprise opportunities found at UoB.

Kyoto University (KU) is located in Kyoto in central Japan. Kyoto Imperial University was founded by imperial ordinance in 1897, the second national university to be established in Japan and was renamed Kyoto University in 1947. KU has 18 graduate schools including 10 faculties, 14 research institutes and 17 education and research centres. $\mathrm{KU}$ is associated with nine Nobel Laureates. In KU, the Office of Society-Academia Collaboration for Innovation (SACI) is responsible for research services. SACI plays three supporting roles, which are currently: endorsing sponsored research, management of IP, and new venture support.

We compare the size of the two universities by comparing the numbers of staff and students in Table 2. There is no significant difference with regard to the numbers of students and staff; suggesting that the outcomes and trends of the two universities in this survey are also directly comparable.

\section{Results and discussion}

Comparisons of industry-university collaboration in the UK and Japan

Funding for collaborative and contract research

In the UK, total funding of university collaborative research, by OSI Research Councils, other UK government departments, and EU governments, increased substantially from $£ 530$ million to $£ 951$ million (about $¥ 95$ billion to $¥ 170$ billion) per year over the past 10 years (Fig. 1a). Similarly, collaborative research funding by SMEs, other commercial business (non-SMEs), and non-commercial organisations, increased from $£ 617$ million to $£ 1166$ million (about $¥ 110$ billion to $¥ 210$ billion) per year (Fig. 1b). When we focus on the total funding by commercial business, we see an increase from $£ 278$ million to $£ 440$ million (about $¥ 50$ billion to $¥ 80$ billion) in the UK per year (Fig. 1c). However, funding by SMEs is much smaller than funding by other commercial businesses.

In Japan, total funding of collaborative research by industry, non-commercial organisations and public society, also increased from $¥ 26$ billion to $¥ 51$ billion (about $£ 140$ million to $£ 280$ million) per year over the past 10 years (Fig. 2a). Funding for contract

Table 2 University of Bristol and Kyoto University

\begin{tabular}{llllllll}
\hline & \multicolumn{3}{l}{ The number of students } & & \multicolumn{3}{l}{ The number of staff } \\
\cline { 2 - 3 } & Total & Undergraduate & Postgraduate & & Total & Academic & Non-academic \\
\hline University of Bristol & 19,470 & 14,040 & 5430 & 5535 & 2610 & 2925 \\
Kyoto University & 22,908 & 13,585 & 9323 & 5432 & 2777 & 2655 \\
\hline
\end{tabular}


research increased from $¥ 101$ billion to $¥ 170$ billion (about $£ 560$ million to $£ 940$ million) per year between 2004 and 2008 but has remained stable since 2009 (Fig. 2b).

Thus, we see that total collaborative research and contract research funding in Japan is smaller than in the UK. Comparing research funding of both collaborative and contract research by commercial business, (at $\backslash 32$ billion to $¥ 50$ billion (about $£ 180$ million to $£ 280$ million) per year (Fig. 2c)) also shows a lower funding level in Japan than in the UK. By contrast, the numbers of research contracts with commercial business, both with SMEs, rising from 4813 to 7260 over 10 years, and non-SMEs, rising from 10,410 to 17,298 in Japan are over double those in the UK, where the numbers of research contracts both with SMEs and with non-SMEs are flat for 10 years (Fig. 3a, b). In particular, the number of research contracts with SMEs in Japan is three times those in the UK.

Then, we examined the funding from, and the numbers of consultancy contracts with SMEs, other commercial business (non-SMEs), and non-commercial organisations in the UK. Consultancy is an important mechanism for the transfer of knowledge from higher education institutions to other parties and can also generate significant revenue. Consultancy revenue in the UK has increased from $£ 218$ million to $£ 400$ million (about $¥ 33$ billion to $¥ 72$ billion) a year (Fig. 4a). Even more remarkable is the increase in the number of contracts with SMEs which increased from 16,467 to 49,944 a year over the last 5 years (Fig. 4 b). There is formally no such consultancy contract with other parties in Japanese universities' reported figures.

\section{Patents, spin-offs and income from TT}

We looked at the reported numbers relating to patents, such as disclosures, applications, and granted patents in the two countries. Numbers reported for Japan on all of these criteria were over double those of UK (Fig. 5a). In particular, the number of granted patents has increased substantially for Japanese universities, from 6570 to 25,945 over the last 5 years (Fig. 5b).

Figure $6 \mathrm{a}, \mathrm{b}$ shows the IP incomes in UK and Japan. There is a big difference between the two countries, the UK incomes of $£ 86$ million (about $¥ 15$ billion) in 2012-2013, being around five times those of Japan, at $¥ 2741$ million (about $£ 15$ million) in 2013 , despite the fact that the numbers of patents reported in Japan are bigger than those in the UK. In the UK, reported income includes sale of shares in spin-off companies and IP income includes non-software licencing, software licencing, and others. In contrast, in Japan, income relies largely on income from patent licencing. The remarkable peak in income from the sale of shares in spin-off companies in 2008-2009 in the UK is accounted for mostly by one higher education institute (HEI) selling its share in a wellestablished company.

Interestingly, the numbers of licences granted are very similar in the UK and Japan over the past decade (Fig. 7a, b). Licences granted by universities have increased smoothly in both countries.

Figure 8a, b shows current trends of spin-offs from universities in both the UK and Japan. In Japan spin-off numbers declined dramatically from 250 per year in 2005 to 50 per year in 2010, since when the number has remained stable. In the UK spin-off 
numbers show no clear trend, with peaks at 226 in 2006-2007 and 273 in 2009-2010, respectively, and the number in 2012-2013 similar to that in 2004-2005 at 150.

\section{Comparisons of technology transfer and industry-university collaboration in UoB and KU} Organisation

In the UoB, the Research Commercialisation team (RCT) in RED advises researchers on how to make the most of a 'technology transfer' opportunity, where there is an invention or new technological development involved. The RCT is composed of one head, one senior manager, two managers and two administrators as of October 2014. The roles of the team are to identify and consider the results of research which might be disseminated via commercial channels, to protect IP rights such as patents, trademarks, design rights and copyright as appropriate, and to identify the best route to market for economic, societal and/or community benefit. At UoB, technology transfer is not undertaken via a separate legal entity, the RCT covers all aspects of commercialisation including the identification of and negotiation with potential partner companies. Support for collaborative or contract research is provided partly via the RCT but also across other teams within RED and within faculties, institutes or schools across the university. UoB does not have an internal venture fund but has close links to Wyvern, a fund originally set up under the government's 'University Challenge Fund programme', and to IP Group, a venture capital provider listed on the London Stock Exchange which specialises in funding university spin-off companies.

In $\mathrm{KU}, \mathrm{SACI}$ is an organisation which takes responsibility for industrial liaison, and research collaboration. SACI provides a gate keeper for companies who are interested in collaboration with the university. SACI welcomes communication from companies interested in licensing technology developed by the university researchers and/or collaborative research with the university. SACI is composed of three departments; Industrial Liaison, Intellectual Property and Licensing, and Legal Affairs. The Industrial

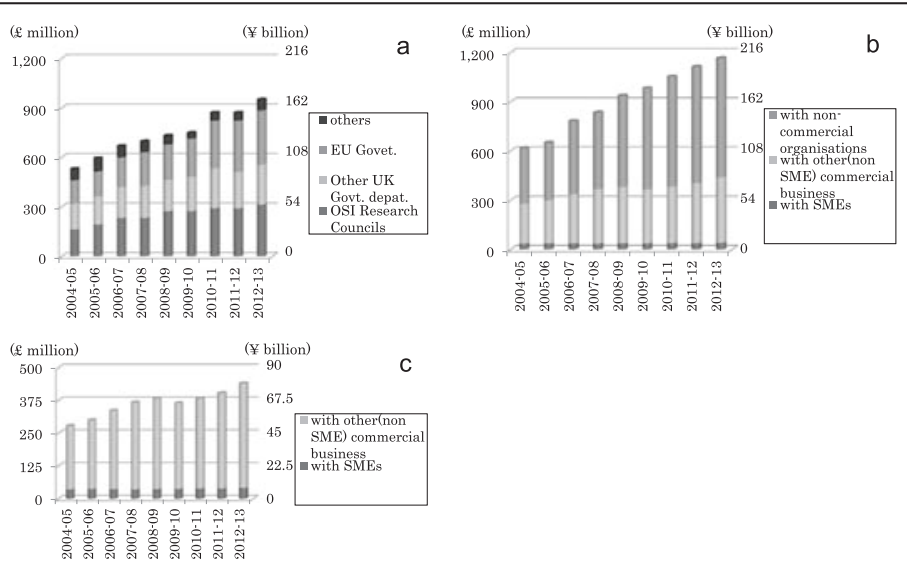

Fig. 1 Total funding of collaborative research and contract research in the UK from 2004-05 to 2012-13. Collaborative research (a) is composed of fund with the Office of Science and Innovation (OSI) research, other UK government department, EU government, and others. Contract research (b) is composed of funds with SMEs, other (non-SME) commercial business, and non-commercial organisations. Contract research with commercial business (c) comprises funds with SMEs and other (non-SME) commercial business. Currency is $£ 1=\backslash 180$, as of November 2014 


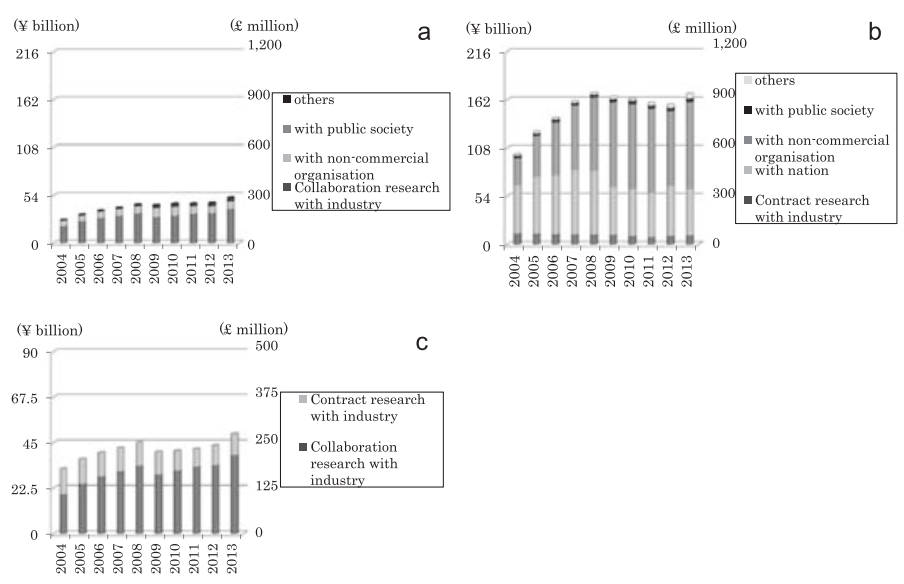

Fig. 2 Total funding of collaborative research and contract research in Japan from 2004 to 2013. Collaborative research (a) is composed of funds with industry, non-commercial organisation, public society, and others. Contract research (b) is composed of funds with industry, nation, non-commercial organisation, public society and others. Research fund with industry (c) comprises collaborative research and contract research. Currency is $£ 1=\backslash 180$, as of November 2014

Liaison department takes care of research collaboration and currently has about 18 staff. In December 2014, SACI also established the Kyoto University Innovation Capital (KUiCap), a venture capital company. SACI takes responsibility for academic collaboration activities across the university. In addition, there are some local offices which are in charge of TT and industrial liaison in faculties, schools and institutes: Kyoto University Medical Science and Business Liaison Office in the Graduate School of Medicine (KUMBL), the Department of R\&D Alliances in Kyoto University Hospital, the Intellectual Property Office in the Center for iPS cells Research and Application, and so on. Their offices have a strong link to SACI through the sharing of information about IP, licencing and industrial collaboration in each area. KU also has contracted with two TLOs. One of them is Kansai TLO, located in the Kansai area in the west of Japan. Kansai TLO strives to contribute to society through TT and research exchange from several universities in the west of Japan and also by supporting venture funded spinoffs. Kansai TLO continuously supports licensing IP from universities and links with
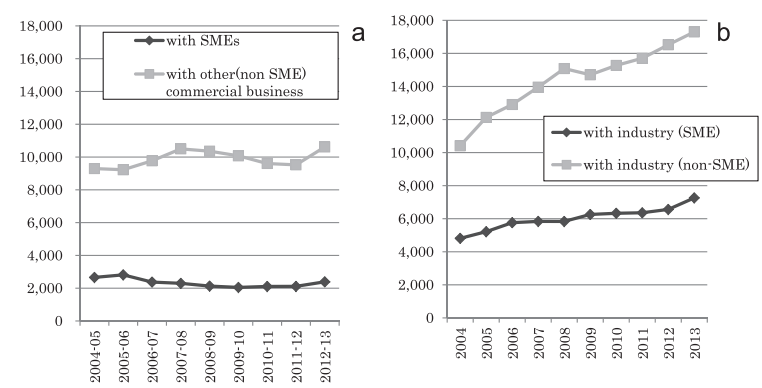

Fig. 3 Numbers of contracts with commercial business in the UK and Japan. The number in the UK from 2004-2005 to 2012-2013 (a) expresses number of contract with SMEs or other (non-SME) commercial business. The number in Japan from 2004 to 2013 (b) expresses number of contract with industry (SME) or industry (non-SME) 
industrial partners who may be interested in commercialising the IP. The other contracted TLO is the Sirankai alumni association's Science and Business Liaison Office, which was established externally as an alumni association of the Graduate School of Medicine. This office mainly drives TT for inventions generated from the Graduate School of Medicine.

As for training for staff, it is hard to improve skills in both universities. In both universities, staff generally improve their experience and knowledge by learning on the job as well as attending specific external courses (for example, from PraxisUnico in UK and the Japan Science and Technology Agency in Japan). In terms of training for university staff and students, both universities offer conferences or workshops covering IP, industrial liaison, and new business creation for new researchers and new academic staff. Staff from both offices also often runs training courses for graduate school students and undergraduates in the faculty related to their specialty.

\section{Technology transfer processes}

In UoB the RCT starts the process by working with research groups so academics understand what might be appropriate for commercialisation and at what stage the RCT should be involved (Fig. 9a). In order to create this understanding, the RCT often gives seminars/workshops to staff and students on IP and commercialisation using external experts, e.g. patent attorneys, generally when requested by the groups/departments. When a researcher believes they may have a specific technology which could be commercialised, they approach the RCT. A RC manager discusses their idea with the researcher and will often suggest more proof of concept work is required ahead of commercialisation. They may also explain why the technology is not appropriate for commercialisation or they will work with the academic to protect and commercialise the technology.

When new projects come to the RCT with a detailed disclosure, a more formal review process by the RCT starts. There is an initial review of whether the potential intellectual property is covered by a contract with a company and/or whether the university has any IP or commercialisation obligations to other research funders. Any such obligations are included within the decision and reviews by the RCT. At weekly RCT meetings, projects reaching a review date and newly disclosed projects are discussed. RCT/UoB files patents

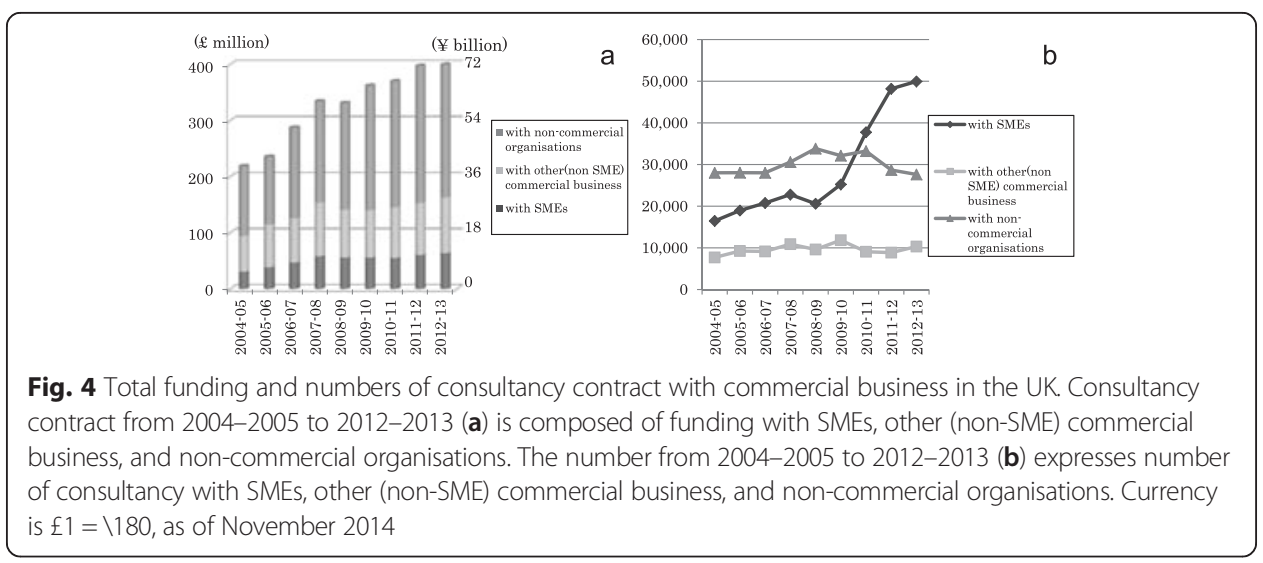




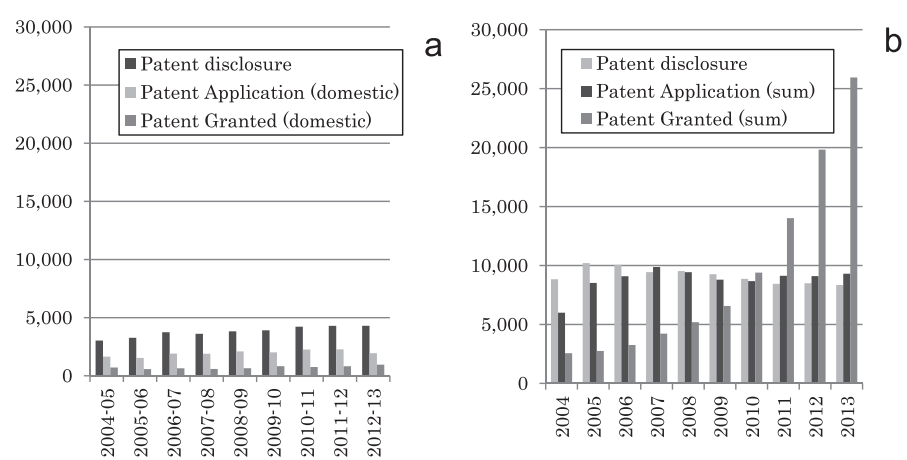

Fig. 5 Patent related numbers in the UK and in Japan. Patent numbers in the UK from 2004-2005 to 2012-2013 (a) contain patent disclosure, patent application (domestic), and patent granted (domestic). Patent numbers in Japan from 2004 to 2013 (b) contain patent disclosure, patent application (sum of domestic and foreign) and patent granted (sum of domestic and foreign)

only where patents are expected to generate a significant commercial value and/or where protection is necessary for commercialisation of a final product or service. The RCT reviews projects at $6,10,18,24$ and 36 months following disclosure or patent filing to maintain momentum towards commercialisation. If a project has been deemed not to have commercial potential and no further activity is warranted, then the project will be closed. Most decisions within the process are delegated by the university (within a set budget) to the RCT so that decisions can be made quickly, facilitating a timely process. When a project is closed or a decision is made not to patent, the RC manager discusses the decision with the lead academic to explain the reasons; reasons can be: 'no commercial interest,' 'no money for investment,' not strong patent,' already published/prior art', etc. In the patent process, key decisions are required 12 and 30 months after a patent is filed. Ahead of patent filing and at these decision points, the RC manager will make a business case to the team, justifying the patent expense in the light of the addressable market, if he/she wishes to proceed to the next step in the patent process. This process was initiated because the costs of patenting can be high; for example UoB can pay up to $£ 8$ thousand for the drafting and filing of a new patent application. If they elect to progress the patent through international (PCT) phase 12 months after filing, this usually costs $£ 6-8$ thousand per filing. The RCT is unlikely to agree to progress to National/Regional phase without an identified commercial partner. Specifically, UoB would not normally prosecute outside of Europe and US unless the costs of this were being met by commercial partners.

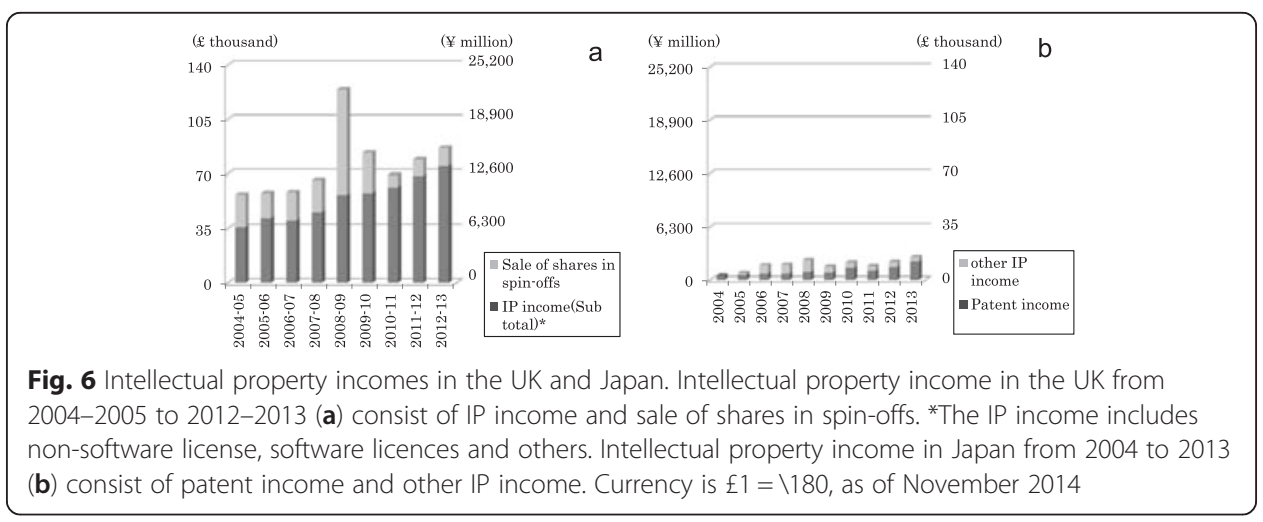




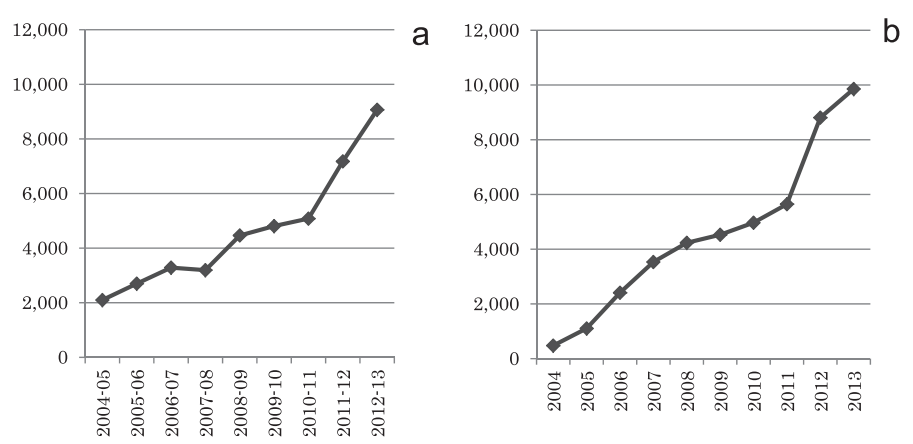

Fig. 7 Numbers of licences granted in the UK and in Japan. The numbers in the UK (a) is sum of granted licences from 2004-2005 to 2012-2013. The numbers in Japan (b) is amount of granted licensed from 2004 to 2013

The university is very concerned with understanding and addressing real market need. In this space there are two types of 'market'. One is the market for the ultimate use of the innovation. The other is the intermediate market of commercial organisations which the university may partner with. Such an organisation normally has a deeper understanding of and expertise in the ultimate market, and can bring their own skills and resources to develop and/or improve the product or service. It is always a challenge to find appropriate organisations which the university may partner with. Despite the number of connections with companies, UoB has relating to collaborative research it can be difficult to identify the right company and the right person within that company for a specific licensing project. The RC staff uses a range of methods to find potential licensee companies, including web searches and their own and the academic's personal networks.

An alternative route to market for new inventions and innovations may be the creation of a spin-off company. A company structure has to be created, investment procured, a management team formed, and many other matters attended to. The RCT sets up spin-off companies as new businesses, and has helped establish 26 new companies, as at September of 2014. Support for new companies is offered via the SETsquared incubator which provides close mentoring, introduction to investors and training as well as the more traditional desk and meeting space.

When an invention is commercialised, any financial return (or equity in the case of a spin-off) is shared between the inventor(s), the school and the central university according to the University of Bristol revenue sharing scheme (http://www.bris.ac.uk/ $\mathrm{red} /$ research-commercial/revenuesharing.html). The scheme aims to incentivise and reward the individuals concerned, the host department/school and the university centrally. In order to incentivise academic involvement in technology transfer, the first call on income is a payment to the individual(s) involved of up to $£ 4$ thousand (about $¥ 720$ thousand). The next call on gross income is the recovery of all outgoings by UoB, for example patent and legal costs, thus reducing the gross income to a net sum. The net sum, up to $£ 15$ thousand (about $¥ 2700$ thousand), is then distributed: $70 \%$ to the individual(s), $15 \%$ to each of the host department/school and the university. Net income from $£ 15$ thousand to $£ 75$ thousand (about $¥ 2.7$ million to $¥ 13.5$ million) is distributed $50 \%$ to the individual(s), and $25 \%$ to each of the host department/school and the 

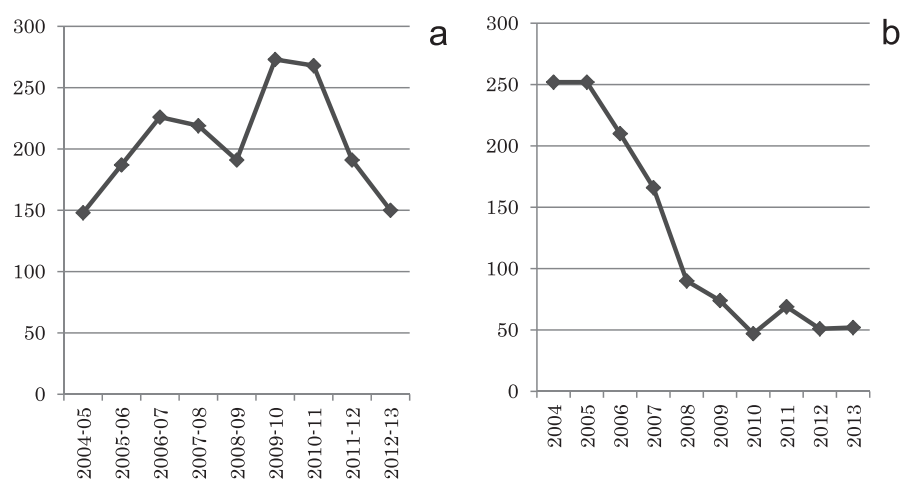

Fig. 8 Number of spin-offs in the UK and in Japan. The numbers in the UK (a) is sum of spin-offs from 2004-2005 to 2012-2013. The numbers in Japan (b) is amount of spin-offs from 2004 to 2013

university. Net income over $£ 75$ thousand (about $¥ 13.5$ million) is distributed one-third to each of; the individual(s), the host department/school and the university.

In KU, the Intellectual Property and Licensing division in SACI starts the process by working with research groups (Fig. 9b), with the same objective as in UoB. Actually, there is more than one office for TT in KU, for example, KUMBL, one of several local offices, supports the Graduate School of Medicine and reports to SACI. The Intellectual Property and Licensing division or these offices provide seminars to faculties and students on IP and commercialisation, similar to those offered in UoB. The KU TT process starts when asked for by the groups themselves with the Intellectual Property and Licensing division directly or through these offices. When researchers develop an invention they believe may be commercialisable, via licensing or new business creation, the Intellectual Property and Licensing division is in charge of the process. The KU process is different to that in UoB. An initial assessment is made as to whether there is an existing interaction between the faculty and an external organisation. When this is not the case, Kansai TLO manages the whole process including patent applications, identifying relevant external organisations, and the process of licencing. Staff in Kansai TLO start by interviewing the researcher's group and get detailed information on what the invention is. Where researchers are already working with external partners, SACI comprehensively checks the processes, such as timing of income and exploitation of IP. In either case, if the invention has novelty based on the preliminary information, it is discussed at a bi-weekly meeting of the patent review committee of SACI, which comprises of faculty members and general managers of SACI, TT specialists, marketing specialists, etc. This committee will decide whether the university should protect the new invention as the property of the university. If the researchers are planning an imminent publication, then the patent and publication processes will be progressed in parallel. When the committee makes a positive decision, IP protection (e.g. patent) will be supported by a university budget. An initial patent filing costs about $¥ 400$ thousand (about £2200). In KU, it takes about 2 months from receiving an innovation application by a researcher in SACI to filing the application at the Japanese Patent Office. The committee will also decide whether an application should proceed to the PCT phase within 12 months after initial filing, whether KU should keep projects into National/Regional phase. However, the committee is unlikely to prosecute outside of Japan unless the costs of this were being met by commercial partners. If a Japanese university makes 


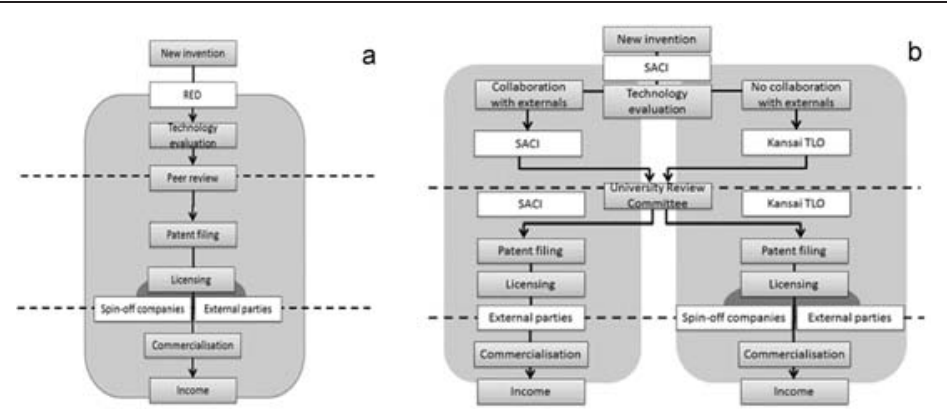

Fig. 9 Technology transfer processes in the University of Bristol (a) and in Kyoto University (b)

the decision to 'keep no longer', the patent is offered to the researchers who may wish to pay maintenance or other fees for IP at their own expense. One of the reasons researchers or the university would pay for a patent is that patents may be taken into account when awarding public grants. There are, therefore, more applications for patents by universities in Japan compared to other countries. It is, however, not usually a criterion for academic promotion in Japan.

As for licensing in $\mathrm{KU}$, where there is no collaboration with externals, the process mirrors that in UoB, Kansai TLO mainly finds appropriate organisations which the university may partner with.

An alternative route to market for new inventions and innovations may be the creation of spin-off companies. KU offers a venture support opportunity which promotes funding to entrepreneurs through linking Kyoto University Innovation Capital (KUiCap) and two Kyoto University Venture Funds (KUVF). TLOs and the KUiCap team work together to identify the route to market. So far, there are 19 venture companies (as of September 2014) supported by two KUVF capital funds. KU also widely showcases patents to companies, institutes and universities on the web.

How royalty is distributed, is laid out in the invention regulation of KU (http:// www.kyoto-u.ac.jp/uni_int/kitei/reiki_honbun/w002RG00000924.html). In the regulation, first of all, inventors can receive $¥ 6$ thousand (about $£ 33$ ) from KU when their patents are filed at the Japan Patent Office. The call on gross income up to $¥ 10$ million (about $£ 56$ thousand) is initially the recovery of all outgoings by $\mathrm{KU}$, for example patent and legal costs, thus reducing the gross income to a net sum. The net sum is then paid $50 \%$ to the individual(s), and $25 \%$ to each of the host department and the university. For gross income over $¥ 10$ million (about $£ 56$ thousand), net income is calculated in the same way and distributed one-third each to the individual(s), the host department and the university.

\section{Patents and revenue from TT}

We looked at patent related activity, licences granted and university revenues in the two universities. Figure 10a, b shows the numbers of invention disclosures, patent applications (domestic and foreign), and patents granted (domestic and foreign) from 2008 to 2013. All the numbers relating to patents were bigger for KU than for UoB. The numbers of invention disclosures, are, on average about 120 per year in UoB, and about 420 per year in KU. The numbers of patent applications are less than 30 per year 


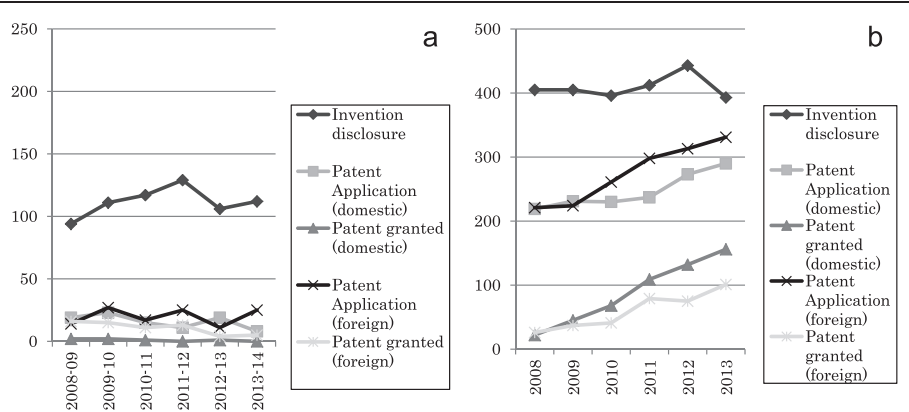

Fig. 10 Numbers of patents in UoB and KU. Number of patents in the UoB from 2008-2009 to 2013-2014 (a) and KU from 2008 to 2013 (b) contain invention disclosure, patent application (domestic), patent granted (domestic), patent application (foreign), and patent granted (foreign)

in $\mathrm{UoB}$, but, in contrast about 250 per year in KU. In KU, over half of patent disclosures are converted into patent applications but less than one-quarter are converted in UoB. Referring to the number of patents granted: in KU, the number has risen substantially over the last 6 years while in UoB numbers have declined, especially since 2011 . Figure 11a, b shows the two university revenues from 2008 to 2013. In UoB, the revenues are composed of non-software licence income, software licence income and other intellectual income. In KU, those are summarised as patents, copyrights and research materials. There were no differences in the revenue received by the two universities before 2009 but the revenues of KU are above those of UoB since 2010, due to a significant increase in patent income.

In this study, we focused on Japanese university's entrepreneurship as represented by industry-university activity and funding, patents, licences and spin-off formation. A comparison of technology transfer in the UK and Japan has provided some insights into whether Japanese entrepreneurship is working and how it might be improved. Relative GDP and population numbers in the two countries might suggest that Japan should be twice as active in industry-university interactions as the UK. However, looking at the number of universities and academics in the two countries would lead us to expect similar levels of activity. In Japan, industry-university collaboration activity started in earnest in 2005 following the Japanese Bayh-Dole Act in 1999 and national university

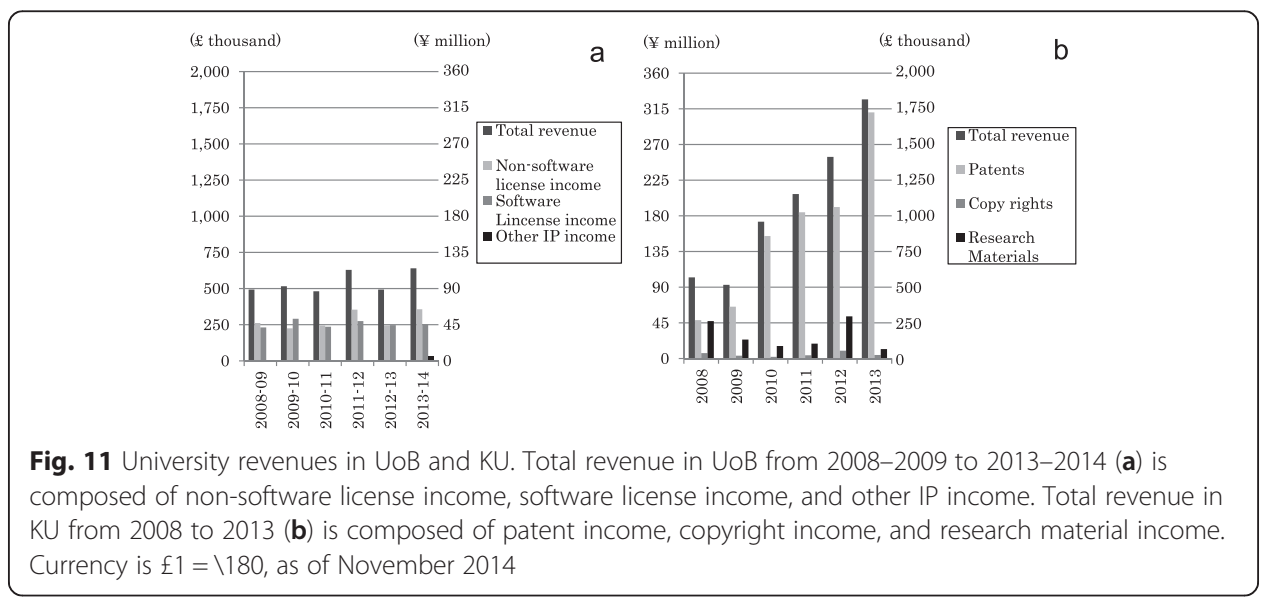


incorporation in 2004 (Shimoda 2005). We found that Japanese universities' entrepreneurship has improved over the past 10 years in all respects except spin-offs.

First, there is some evidence that Japanese universities are successful in their enterprise endeavours: for example it is remarkable that in Japan, the number of contracts with industry, including large enterprises and SMEs, has doubled since 2005 while in the UK the number of contracts is almost flat over the same time period. The number of licences granted from Japanese universities has increased over 10 fold when compared to the number in 2004 while in the UK the number of licences granted increased about 4-fold over the same timescale. That means engagement with externals has improved over the last decade, and is showing a positive trend.

Other evidence shows more moderate entrepreneurial success in Japanese universities: for example, although, the total funding of collaborative research and contract research almost doubled from $¥ 128$ billion (about $£ 750$ million) in 2003 to $¥ 220$ billion (about $£ 1298$ million) in 2013 this occurred in two phases with the increase all taking place between 2003 and 2008 and stagnating since 2008. It is possible that this was influenced by the global financial crisis of 2007-2008 as the figures from 2009 to 2013 of our study remain stable. In the UK, total collaborative research and contract research also almost doubled from $£ 1440$ million (about $¥ 245$ billion) in $2003-2004$ to $£ 2658$ million (about $¥ 451$ billion) in $2012-2013$, but in contrast to Japan, the growth has continued throughout the period. The total collaborative and contract funding in the UK is around twice that in Japan. We speculate that the different sizes of collaborative and contract funding in the two countries could be due to the almost 20-year time difference over which the activity has developed in the two countries, activity in the UK commencing from 1992 and in Japan from 2004.

Our study has also suggested some areas where Japanese universities could improve their entrepreneurship. Although, we found that securing patents from disclosure to grant works well in Japan, we also found that this has resulted in large and increasing patent related numbers over the last 10 years so that universities may arguably now maintain too many patents with associated large cost commitments. IP income in Japanese universities has improved moderately in the last decade, but is still significantly smaller than that across UK universities suggesting that the return on investment for patent expenditure may be inadequate. We suggest that IP management inside Japanese universities is not yet fully mature and Japanese universities should immediately review their patent filing processes and TT activities to improve the current situation. In order to continue to develop university entrepreneurship in Japan in all areas universities should select patents which are truly innovative and will generate a significant commercial benefit for the final commercialisation partner. Japanese universities should streamline technology transfer processes which are complicated, obscure and difficult to understand both by university staff and potential partners. They also should enhance both the volume and quality of technology transfer activity, continuing to employ skilled experts (e.g. Registered Technology Transfer Professional (RTTP) in the Alliance of Technology Transfer Professionals (ATTP)) and improving/building on the skills of current employees through Continuing Professional Development (CPD), as Lockett and Wright (2005) mentioned the expertise of the staff is important to success in commercialisation. Perhaps an area in which Japanese universities need to improve entrepreneurship the most is in the area of spin-offs-in Japan, the numbers of spin-offs created has been flat over the last 5 years. Although licencing to established 
companies may be the most efficient way to exploit most IP, in some cases, particularly if the IP is a platform technology or when there is a lack of suitable clients, creating a spin-off company may be the best choice. But in Japan, it seems currently to be hard to create a spin-off company. We speculate that Japan spin-off numbers are much lower than those in the UK, because Japanese investors and bankers are generally risk averse so that financing early stage companies is even more challenging in Japan than in the UK. This also means that there are very few experienced commercial managers prepared to work with a start-up or spin-off company. This may lead to companies being formed without an effective commercial strategy or plan.

Within the Triple helix innovation model, the role of government is also central and the Japanese government could contribute to improving a balanced Triple Helix innovation system in Japanese entrepreneurship through the implementation of support organisations offering grants to SMEs (including spin-off companies) building on university research, similar to Innovate UK in the UK and/or finance incentives for early stage investors similar to the UK EIS/SEIS schemes and in encouraging the development of commercial expertise in universities via CPD and professional qualifications such as RTTP.

It is also interesting to look at one study comparing US and Japanese entrepreneurship to further test our hypothesis above. University entrepreneurship in the US started in 1980 and is, arguably, the most successful in the world. In comparing university entrepreneurship between Japan and US, Kneller (2007) focused on university royalty income, university start-up companies and research collaboration in Japan from 1990s to 2004. Universities income in 2003 in the US was already over 200 times that in Japan. In the US, the number of university start-up companies was 200 300 per year from 1994 to 1999, then increased to over 300 per year since 2000. The number of Japanese university start-up companies increased about 25 30 per year from 1990 to 1997, then remarkably gained over 50 per year since 1998 and the TLO Act. Japanese university TLOs have less experience as this activity commenced in 1998 following the new act, university royalty was low and business prospects for most start-up companies was more limited than their US counterparts. There was a definite difference in university entrepreneurship between the US and Japan, as of 2003. In contrast, in Japan, research engagement with companies increased rapidly between 2000 and 2004, especially with large companies. Japanese companies and university faculty may seek out collaboration with partners more readily than their US counterparts. In the US, whereas, faculty may form start-up companies more easily than complicated negotiation between universities and existing companies. These trends of Japanese university activities (including low royalty, small number of start-up companies, and high number of research collaboration in the study) are close to our outcomes.

There are limitations in this study, which indicate possible additional areas for future study. One limitation is that we focus here on just a comparison of industry-university collaboration activity between two countries, the UK and Japan. We have not conducted wider comparisons across other European, Asian, or North American university systems. A survey across other countries is needed to identify how successful Japanese universities' entrepreneurial activity is in a world context. In addition, we focused on just 10 years for our study of the two countries and 5 years for the two universities though it can be argued that it took US universities between 10 and 20 years to create a stable and mature professional TT system 
(Mowery et al. 2001). However, we expect that the comparison conducted through this study will allow a review of Japanese universities' commercialisation mechanisms and accelerate research commercialisation and also might provide information to review entrepreneurial and TT activity and process in UK universities'.

\section{Conclusions}

From this survey, we found that that university size, revenue, activity and processes are very similar between the UK and Japan and between UoB and KU. Japanese universities' entrepreneurship is improving as evidenced by survey data over the past 10 years. However, Japanese universities currently possess, arguably, too many patents resulting in significant pressure on their budgets. They also receive relatively low income from patents suggesting an inadequate return on investment. Finally, the number of Japanese spin-offs created fell significantly between 2005 and 2010, since when the number has remained at around 50 per year suggesting an immature situation with regards to creation of spin-offs to develop universities' IP.

While individual universities can improve elements of the enterprise system and support, as proposed in these conclusions, we suggest that most improvement is to be gained by a review of government and higher education policy and strategy to encourage university entrepreneurship, as happened when the UK incorporated impact as a measure within the REF, directly affecting university funding by government.

We conclude that Japanese universities' entrepreneurship has developed significantly over the past decade and is now working well but could improve by implementing the following recommendations and learning from some specific UK university and governmental activity:

- Review of university policy: create new national policy for improved research commercialisation

- Review of patent strategy: select patents which are truly innovative and will generate a significant commercial benefit for the final commercialisation partner

- Review of technology transfer process: streamline the processes which are complicated, obscure and difficult to understand both by university staff and potential partners

- Improvement of technology transfer skills: enhance both the volume and quality of technology transfer activity, continuing to employ skilled and well qualified experts

- Contribution of governmental funding support: offer targeted grants to SMEs and/ or spin off companies building on university research

\section{Methods}

\section{Comparison of industry-university activity in the UK and Japan}

In this survey, we use two large datasets: for UK: the results of the Higher EducationBusiness and Community Interaction (HE-BCI) survey for UK higher education institutions by the Higher Education Funding Council for England (HEFCE), referring to the 9 academic years from 2004-2005 to 2012-2013 (HEFCE (2004-2013)), and for Japan: the results of industry-university collaboration survey by the MEXT, referring to the 10 
academic years from 2004 to 2013 (MEXT (2004-2013)). We also collected any other relevant information: for the UK, Innovate UK (http://www.innovateuk.org/), KTP (https://connect.innovateuk.org/web/ktp), and PraxisUnico (http://www.praxisunico. org.uk/) on the web, respectively, and for Japan, UNITT (http://unitt.jp/en), and Kansai Technology Licensing Organisation (Kansai TLO) (http://www.kansai-tlo.co.jp/english/ ) on the web, respectively.

We, first, focus on research funding; in particular, collaboration and contract research with commercial business, and next focus on patent-related activity, IP income and spin-offs in these data.

In order to facilitate comparisons between the different datasets which report in different currencies, we show all financial figures in both $£$ and $¥$, using an exchange rate of $£ 1=¥ 180$ and $€ 1=£ 0.77=¥ 140$, as of November in 2014. There are slightly different, though similar, definitions of 'research funding' in the surveys. The definitions of collaborative research and contract research in the UK are as follows: 'collaborative research' includes research projects with public funding from at least one public body, and a material contribution from at least one external non-academic collaborator, and, by contrast, 'contract research' includes contract numbers and income identifiable by the institution as meeting the specific research requirements of external partners, excluding any already returned in collaborative research involving public funding and excluding basic research council grants. In Japan, there are two types of funding definition. One is collaborative research where both university and external partners produce something and share outcomes altogether under a contract. The external partners include commercial business, public bodies or non-commercial organisations. The other, contract research, is defined as research under which externals commit specified projects to universities under a contract. The outcomes from contract research are normally owned by the universities but then are purchased by externals which may include commercial business, public societies, non-commercial organisations or government. The UK data classifies collaboratives and contracts asbeing with SMEs or non-SMEs, reporting financial numbers and volume under each category. The Japanese data does not make this distinction but reports only the numbers (volume) with SMEs and non-SMEs. The two countries also have slightly different though similar definitions of SME. In the UK, SMEs are defined as enterprises which employ fewer than 250 persons and which have an annual turnover not exceeding €50 million (about $£ 40$ million, $¥ 7$ billion), and/or an annual balance sheet total not exceeding $€ 43$ million (about $£ 33$ million, $¥ 6$ billion). SMEs include micro, small and medium enterprises and sole traders. In Japan, SMEs include enterprises which employ fewer than 300 persons and which have a capital amount not exceeding $¥ 300$ million (about $£ 1.7$ million, $€ 2.1$ million). SMEs include micro, small and medium enterprises and sole traders.

Secondly, we focus on the numbers of patents reported in each survey which includes patent disclosures, patent applications and granted patents. We also look at IPrelated income and the numbers of licences granted. In the UK, according to the HEBCI survey, IP income includes non-software, software income and other IP income. In Japan, it includespatents and others. We also investigate the numbers of spin-offs created by universities and academics in the two countries. 


\section{Comparison of industry-university activity in UoB and $\mathrm{KU}$}

We undertook an empirical survey for industry-university activity, which includes the TT processes, by interviewing each expert who manages the research commercialisation service in UoB and KU. In UoB, we also researched from the web information relating to RED (http://www.bris.ac.uk/red/). In KU, we also researched from the SACI webpage (http://www.saci.kyoto-u.ac.jp/en/). We next focus on the numbers of patents reported and university incomes for the last 5 or 6 years i.e. academic years from 2008 to 2013 in UoB and KU. Data for UoB and KU are submitted every year to the HE-BCI survey and the industry-university collaboration survey, respectively.

\section{Endnotes}

${ }^{1}$ This is results from the Population Estimates in the Ministry of Internal Affairs and Communications.

${ }^{2}$ This is results from the UK population in the Office for National Statistics.

${ }^{3}$ The data is from the results of 'GDP (current US\$)' of World DataBank in the World Bank as of June 9th, 2015.

Competing interests

The authors declare that they have no competing interests.

\section{Authors' contributions}

$\mathrm{TI}$ conceived this research, carried out data collection in the UK and Japan and that in University of Bristol, analysed, drafted. TK carried out data collection in Kyoto University, analysed. SS analysed and coordinated this research. All authors read and approved the final manuscript.

\section{Acknowledgements}

We would like to thank Prof Lars Sundstrom, Dr David Langley, and the Research Commercialisation Team for their help and support with this paper. This work was supported by two foundations: the John Mung Program in Kyoto University and the Astellas Foundation for Research on Metabolic Disorders.

\section{Author details}

${ }^{1}$ Research and Enterprise Development, University of Bristol, Tyndall Avenue, Bristol BS8 1TH, UK. ${ }^{2}$ Office of Society-Academia Collaboration for Innovation, Kyoto University, Yoshida-Honmachi, Sakyo-ku, Kyoto 606-8501, Japan.

Received: 15 September 2015 Accepted: 26 January 2016

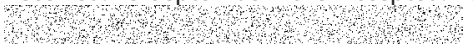

\section{References}

Bergman, E. M. (2010). Marshall's dilemma and commercialization of European Research. http://www.ekf.vsb.cz/export/ sites/ekf/projekty/cs/weby/esf-0116/databaze-prispevku/clanky_ERSA_2010/ERSA2010finalpaper363.pdf. Accessed 22 December 2014.

Breznitz, S. M. (2011). Improving or impairing? Following technology transfer changes at the University of Cambridge. Regional Studies, 45, 463-478. doi:10.1080/00343401003601909.

Carayannis EG, Barth TD, and Campbell DFJ. (2012). The Quintuple Helix innovation model: global warming as a challenge and driver for innovation. Journal of Innovation and Entrepreneurship. doi:10.1186/2192-5372-1-2.

Decter, M., Bennett, D., \& Leseure, M. (2007). University to business technology transfer-UK and USA comparisons. Technovation, 27, 145-155.

D'Este, P., \& Patel, P. (2007). University-industry linkages in the UK: what are the factors underlying the variety of interactions with industry? Research Policy, 36, 1295-1313.

DTI. (1993). Realising our potential: a strategy for science engineering and technology. London: HMSO.

DTI. (2001). Science and innovation strategy 2001. London: Department of Trade and Industry.

Geuna, A., \& Nesta, L. J. J. (2006). University patenting and its effects on academic research: the emerging European evidence. Research Policy, 35, 790-807.

Geuna, A., \& Rossi, F. (2011). Changes to university IPR regulations in Europe and impact on academic patenting Research Policy, 40, 1068-1076.

HEFCE. (2004-2013). High education-business and community interaction survey-2004-05 to 2012-13. http://www hefce.ac.uk/kess/hebci/. Accessed 17 July 2015.

Higher Education Statistics Agency, Online Statistics. (2012-13). For student: https://www.hesa.ac.uk/index. php?option=com_content\&view=article\&id=1897\&ltemid=634, for staff: https://www.hesa.ac.uk/index. php?option=com_content\&view=article\&id=1898\&ltemid=634. Accessed 17 July 2015.

Jacobsson, S., Lindholm-Dahlstrand, A., \& Elg, L. (2013). Is the commercialization of European academic R\&D weak? - a critical assessment of a dominant belief and associated policy responses. Research Policy, 42, 874-885. 
Kneller, R. (2007). The beginning of university entrepreneurship in Japan: TLOs and bioventures lead the way. The Journal of Technology Transfer, 32, 435-456.

Lockett, A., \& Wright, M. (2005). Resources, capabilities, risk capital and the creation of university spin-out companies. Research Policy, 34, 1043-1057.

Looy, B. V., Landoni, P., Callaert, J., Pottelsberghe, B. V., Sapsalis, E., \& Debackere, K. (2011). Entrepreneurial effectiveness of European universities: an empirical assessment of antecedents and trade-offs. Research Policy, 40, 553-564.

Macdonald, S. (2009). Seducing the goose: patenting by UK Universities. http://citeseerx.ist.psu.edu/viewdoc/ download?doi=10.1.1.474.1115\&rep=rep1\&type=pdf. Accessed 22 December 2014

MEXT. (2011). The 4th science and technology basic plan of Japan. http://www.mext.go.jp/component/english/_icsFiles/ afieldfile/2012/02/22/1316511_01.pdf. Accessed 16 November 2015.

MEXT. (2004-2013). The University-industry collaboration survey in 2004 to 2013. www.mext.go.jp/a_menu/shinkou/ sangaku/sangakub.htm. Accessed 17 July 2015.

MEXT. (2013). Statistics data for universities, junior colleges, College of technology. www.mext.go.jp/english/statistics/. Accessed 17 July 2015

Motohashi, K., \& Muramatsu, S. (2012). Examining the university industry collaboration policy in Japan: patent analysis. Technology in Society, 34, 149-162.

Mowery, D. C., Nelson, R. R., Sampat, B. N., \& Ziedonis, A. A. (2001). The growth of patenting and licensing by U.S. universities: an assessment of the effects of the Bayh-Dole act of 1980. Research Policy, 30, 99-119.

Mowery, D. C., \& Sampat, B. N. (2005). The Bayh-Dole Act of 1980 and University-Industry Technology transfer: a model for other OECD governments? In A. N. Link (Ed.), Essays in honor of Edwin Mansfield: the economics of $R \& D$, innovation, and technical change (pp. 233-245). New York: Springer.

REF impact (2014). http://www.hefce.ac.uk/rsrch/REFimpact/ Accessed 16 November 2015.

Salter, A., D'Este, P., Pavitt, K., Scott, A., Martin, B., Geuna, A., et al. (2000). Talent, not technology: the impact of publicly funded research on innovation in the UK. UK: Science Policy Research Unit, University of Sussex.

Shimoda, R. (2005). Intellectual property management of national university corporations. Shift to institutional ownership and its new challenges. International Journal of Intellectual Property -Law, Economy and Management, 1, $37-45$.

Siegel, D. S., Veugelers, R., \& Wright, M. (2007). Technology transfer offices and commercialization of university intellectual property: performance and policy implications. Oxford Review of Economic Policy, 23, 640-660.

Takahashi, M., \& Carraz, R. (2009). Academic patenting in Japan: illustration from a leading Japanese university. In P. K. Wong (Ed.), Academic entrepreneurship in Asia: the role and impact of universities in national innovation systems (pp. 86-107). Cheltenham: Edward Elgar.

Valentin, F., \& Jensen, R. F. (2007). Effects on academia-industry collaboration of extending university property rights. Journal of Technology Transfer, 32, 251-276.

Walsh, J. P., Bada, Y., Goto, A., \& Yasaki, Y. (2008). Promoting university-industry linkages in Japan: faculty responses to a changing policy environment. Prometheus: Critical Studies in Innovation, 26, 39-54.

Willets, D. (2014). https://uww.gov.uk/government/speeches/contribution-of-uk-universities-to-national-and-local-economicgrowth Accessed 16 November 2015.

\section{Submit your manuscript to a SpringerOpen ${ }^{\circ}$} journal and benefit from:

- Convenient online submission

- Rigorous peer review

- Immediate publication on acceptance

- Open access: articles freely available online

- High visibility within the field

- Retaining the copyright to your article 